\title{
Avaliação da Qualidade de Filés de Pescada Gó
}

Consuelo Lúcia Sousa de Lima (I), Elisa Cristina Andrade Neves (I), Lúcia de Fátima Henriques Lourenço (I), Luciany do Socorro de Oliveira Sampaio (I), Juliana Laura Medeiros Vaughan (I), Rafaela Santos Oliveira da Silva (I)

(I) UFPA - Universidade Federal do Pará (Rua Augusto Corrêa, 01 - Guamá. CEP 66075-110. )

\section{Resumo}

Os pescados estão entre os produtos de origem animal mais suscetíveis à deterioração, devido ao $\mathrm{pH}$ próximo da neutralidade, à elevada atividade de água nos tecidos e aos altos teores de nutrientes. Por isso exigem cuidados especiais durante toda manipulação, desde a captura até a comercialização para que as suas características microbiológicas, sensoriais, físico-químicas e nutricionais permaneçam viáveis ao consumo. Embora o pescado apresente uma contaminação primária, a partir de ecossistemas aquáticos contaminados, o manuseio após a captura, representado pelas etapas de beneficiamento, conservação e armazenamento, é referido como o fator determinante da qualidade microbiológica do produto final. $\mathrm{O}$ objetivo deste trabalho foi avaliar a qualidade microbiológica e físico-química de filés de pescada gó (Macrodon ancylodon) com e sem pele, produzidos em indústria localizada no nordeste do Estado do Pará. Nas 30 amostras de filés com pele e 24 sem pele foram feitas análises de, Salmonella spp, Estafilococos coagulase positiva, contagem de coliformes termotolerantes e de aeróbios mesófilos e psicrotróficos que seguiram metodologias descritas no Compendium of Methods for the Microbiological Examination Foods. Também foram determinados valores de $\mathrm{pH}$ e de Bases Voláteis Totais (BVT) segundo os métodos analíticos físico-químicos para controle de produtos cárneos e seus ingredientes. Não foi detectada a presença de, Salmonella spp, e estafilococo coagulase positiva só foi isolado em duas

\footnotetext{
Referência:

Consuelo Lúcia Sousa de Lima, Elisa Cristina Andrade Neves, Lúcia de Fátima Henriques Lourenço, Luciany do Socorro de Oliveira Sampaio, Juliana Laura Medeiros Vaughan, Rafaela Santos Oliveira da Silva.Avaliação da Qualidade de Filés de Pescada Gó. In: Anais do 12을 Congresso Latinoamericano de Microbiologia e Higiene de Alimentos - MICROAL 2014 [= Blucher Food Science Proceedings, num.1, vol.1]. São Paulo: Editora Blucher, 2014.

DOI 10.5151/foodsci-microal-107
} 
amostras de filé com pele, dentro dos limites da legislação. A contagem de coliformes não ultrapassou 2,7 log NMP/g e em 9,3\% das amostras foram detectadas valores superiores a $7 \mathrm{log} \mathrm{UFC} / \mathrm{g}$ para mesófilos e psicrotróficos sendo que $38,9 \%$ e 7,4\% apresentaram-se acima das especificações para o pH e BVT, respectivamente. As amostras de filés analisadas não oferecem risco à saúde dos consumidores.

Palavras-Chave: Análises, Contaminação, Peixes Agência de Fomento: 